\title{
DIAGNÓSTICO DE PDP DE UMA EMPRESA DO RAMO MOVELEIRO
}

Flávia Motta Corvello (flaviamcorvello@gmail.com) - Universidade de Brasília, UnB. Sanderson César Macêdo Barbalho (sandersoncesar@unb.br) - Universidade de Brasília, UnB. Jéssica Fernanda Bertosse Marques (jessicafbertosse@ hotmail.com) - Universidade de Araraquara, UNIARA.

\section{RESUMO}

As Pequenas e Médias Empresas (PMEs) possuem grande influência econômica no mercado mundial, porém, para se manterem competitivas, devem apresentar grande capacidade inovativa e para produção de produtos inovadores, o que se torna mais viável quando a empresa apresenta um setor bem definido de Processo e Desenvolvimento de Produtos. O trabalho apresenta um estudo de caso referente ao diagnóstico do Processo de Desenvolvimento de Produtos (PDP) de uma empresa do ramo moveleiro. Foi utilizado um framework para auxiliar a identificação e análise dos elementos de PDP presentes na empresa estudada. Os resultados mostram que a empresa não possui um setor bem definido para o desenvolvimento de novos produtos, assim como não possui uma equipe voltada para tal. Em relação às técnicas, não é aplicada nenhuma ferramenta bem estruturada para a gestão do PDP, e as principais decisões do processo são tomadas diretamente pelo diretor da empresa.

Palavras chave: Diagnóstico, PDP, PMEs. 


\section{INTRODUÇÃO}

O Processo e Desenvolvimento de Produtos (PDP) está na interface entre mercado e empresa, e cabe a ele identificar as necessidades do mercado e dos clientes, assim como as possibilidades tecnológicas e propor soluções por meio do desenvolvimento de um produto de qualidade que atenda aos requisitos identificados, obtendo produtos mais competitivos (ROZENFELD et al., 2006).

Entretanto, a maturidade do PDP em pequenas e médias empresas (PMEs) é diferente da realidade apresentada em publicações sobre o desenvolvimento de produtos em geral, os quais focam em grandes empresas multinacionais, principalmente do ramo automobilístico (TOLEDO; SIMÕES, 2010).

Diante deste cenário e da importância de um setor de PDP estruturado para melhor competitividade de PMEs, a utilização de um framework de diagnóstico do processo de desenvolvimento de produtos destas empresas se apresenta como uma maneira de identificar as falhas e lacunas da empresa nesse aspecto, e propor melhorias a serem incorporadas nessas empresas.

Assim, o objetivo deste trabalho é aplicar um framework de diagnóstico do desenvolvimento de produtos em uma empresa de pequeno porte no setor moveleiro, apresentando suas análises e resultados. O tópico seguinte apresenta a revisão teórica do trabalho. Em seguida é apresentada a metodologia da pesquisa, seguida do estudo de caso e as conclusões.

\section{REVISÃO TEÓRICA}

Rozenfeld et al. (2006) afirmam que para desenvolver produtos são necessárias várias atividades que abrangem desde a identificação das necessidades do mercado e das possibilidades e restrições tecnológicas, e que possibilitam chegar às especificações de projeto necessárias ao desenvolvimento do produto.

Mendes e Toleto (2012) concluíram que existem atividades relacionadas às práticas de gestão das empresas que podem determinar se os projetos de novos produtos serão bem ou malsucedidos, como a relação entre os projetos de produtos e a estratégia da empresa, a identificação do potencial de mercado, a capacidade de traduzir as necessidades dos clientes em características dos produtos, a inteligência gerencial e o relacionamento com a gestão do projeto, a qualidade da realização das primeiras fases do PDP e a agilidade de integração funcional durante essas fases. 
Complementando a importância das atividades relacionadas às práticas de gestão, Manthey et al. (2017), ao estudar a competitividade de Pequenas e Médias Empresas, afirmam que se estas empresas pretendem competir com base em inovação de produtos, devem também, além de aumentar a capacidade de inovação de produtos, melhorar seus processos e habilidades para inovações organizacionais, ou seja, possuir capacidade de adequação e inovação em seus processos para o desenvolvimento de inovações.

A figura 1 apresenta uma síntese da ferramenta para a caracterização do PDP na empresa utilizada neste trabalho. A parte esquerda da síntese apresenta o framework de diagnóstico proposto por Wheelwright e Clark (1992), enquanto a soma ao modelo de referência foi proposta por Barbalho e Rozenfeld (2004), e posteriormente utilizada em Ferreira e Barbalho (2014).

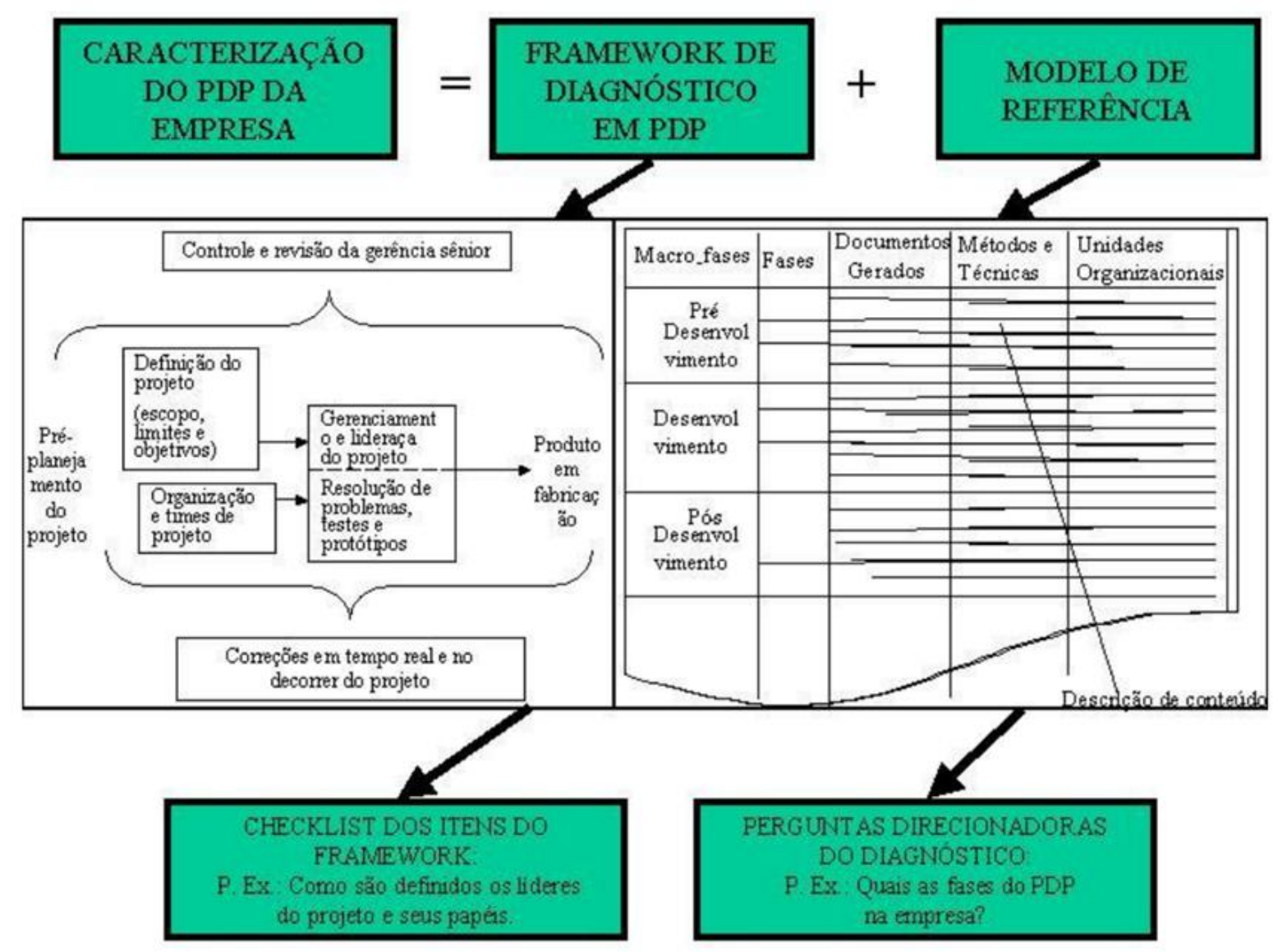

FIGURA 1 - Framework. Fonte: Barbalho e Rozenfeld (2004)

Ferreira e Barbalho (2014) utilizaram o framework proposto por Barbalho e Rozenfeld (2004), que tem como objetivo detalhar e caracterizar cada fase do setor de DP, discriminando seus 
documentos, informações, unidades organizacionais, métodos e técnicas, para realizar o diagnóstico do PDP de uma empresa de médio porte do setor têxtil. O estudo em questão aplicou com êxito o framework proposto e identificou algumas limitações características de uma empresa de médio porte, como a falta de gestão de projetos e falta de mapeamento dos processos das empresas, assim como na forma de identificação de melhoria e diferenciação na função estratégica do PDP.

\section{METODOLOGIA}

O presente trabalho trata de um estudo de caso (Yin, 2000), descritivo, qualitativo, com aplicação do Framework proposto por Barbalho e Rozenfeld (2004) em uma empresa pequena empresa do setor moveleiro. Os dados foram obtidos através de observação direta da empresa e análise documental.

A escolha da empresa se deu pela facilidade de acesso aos dados e pelo interesse das empresas em melhorar o seu PDP. Desta forma, foi possível acessar informações relativas à hierarquia da empresa, identificação dos responsáveis pelas tomadas de decisões, assim como pela execução das atividades. Foi ainda possível acessar os documentos gerados em cada fase do PDP, e identificar sub-etapas e movimentações relacionadas ao desenvolvimento de novos produtos.

O framework de pesquisa utilizado foi escolhido em função de haver literatura anterior utilizando-o, o que permitiria um comparativo dos resultados desse estudo com as aplicações anteriores desse framework.

\section{ESTUDO DE CASO}

A empresa analisada é uma indústria do setor moveleiro localizada no interior do estado de São Paulo que atua no mercado há mais de 20 anos. A principal linha de produtos produzida pela empresa é a de cadeiras de escritório, porém, trata-se de uma empresa flexível quanto à sua produção, definindo seus produtos de acordo com a necessidade de curto prazo do mercado. Por exemplo, durante a pandemia a empresa passou a produzir máscaras contra o COVID.

A empresa possui 60 funcionários, os quais estão distribuídos conforme o organograma apresentado na figura 2. 


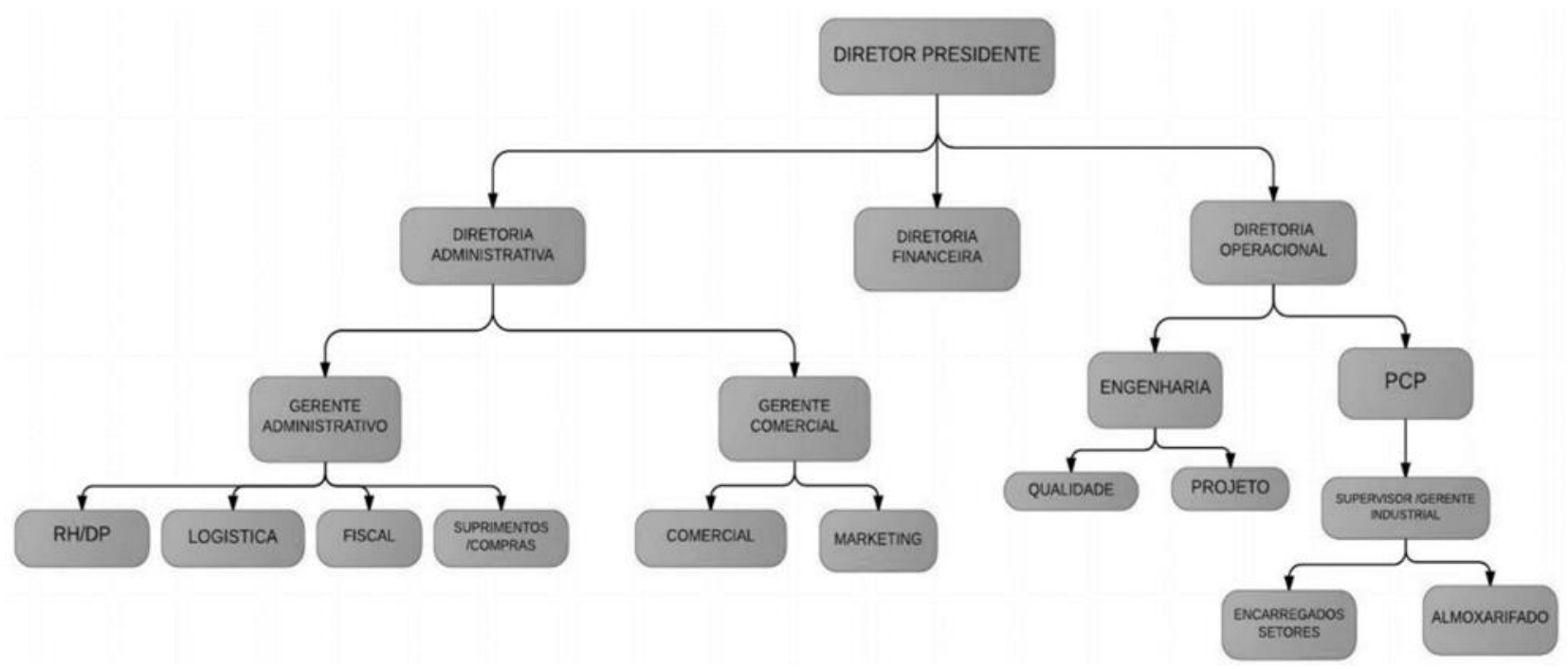

FIGURA 2 - Organograma de hierarquia da empresa pesquisada. Fonte: O próprio autor.

A observação permitiu identificar que a empresa não possui um setor de Projeto e Desenvolvimento de Produtos bem definido, sendo que o projeto de novos produtos é composto pelo Diretor Presidente, por membros da Diretoria Administrativa e do núcleo operacional. O setor de projeto definido pela empresa pertencente à área de Engenharia, como pode ser observado na figura 2, não abrange todas as fases do PDP, possuindo apenas o projetista como integrante do setor, o qual é responsável pelos desenhos técnicos dos produtos em desenvolvimento. Os projetos são desenvolvidos a partir das necessidades do mercado, captadas com base em uma carteira fixa de clientes e eventuais encomendas. Outro canal de análise de mercado é a observação de licitações, que apontam as cotações mais recentes desejadas pelos clientes da área pública. Esta estratégia é classificada como de curto prazo, sendo que a empresa não apresenta um planejamento estratégico para médio e longo prazo. O setor responsável pela recepção das informações relacionadas aos novos produtos é o setor comercial, o qual analisa e traduz estas informações e, em seguida, compartilha com o setor de engenharia responsável pelo desenvolvimento de produtos. Este desenvolve o escopo do projeto e devolve ao setor comercial. $\mathrm{O}$ departamento comercial recebe a requisição do produto e encaminha à Diretoria Administrativa que determinará a viabilidade da execução do projeto de acordo com os 6 maquinários da fábrica. Quando aprovada a requisição, o projeto é encaminhado ao setor de Engenharia, onde será feito o desenho técnico do produto, com todas as especificações, que darão origem ao memorial descritivo, único documento oficial gerado no processo de desenvolvimento do produto, a partir do qual é possível fazer a análise de custos de matériaprima e de produção. Este memorial é encaminhado à Diretoria Administrativa, que deverá 
aprovar a comercialização do produto. $\mathrm{O}$ acompanhamento do projeto é feito pelo setor de Engenharia desde o escopo do projeto até a aprovação para a comercialização pela Diretoria Administrativa, garantindo suporte ao processo de projeto do produto. Após aprovada a comercialização e execução do projeto, um protótipo é criado para a avaliação do produto, resolução de possíveis problemas, determinações técnicas e testes de resistência física do produto, a fim de validar o projeto e realimentar o memorial descritivo. Todas as validações são encaminhadas às Diretorias Operacional e Administrativa. O núcleo operacional, composto pelo setor de Engenharia e PCP, acompanha todo o desenvolvimento do produto e produção da requisição do cliente, de forma a garantir qualidade e pontualidade ao desenvolvimento do produto. $\mathrm{O}$ acompanhamento da produção por parte do setor de engenharia permite correções em tempo real ao longo da produção do produto, viabilizando a produção e garantindo a qualidade final do produto. Todas as alterações feitas ao longo do processo de fabricação devem ser atualizadas no memorial descritivo do produto. A análise da empresa mediante o uso do framework, permitiu identificar as principais características do PDP da empresa pesquisada, como apresentado no Quadro 1. 
QUADRO 1 - Framework do Desenvolvimento de Produto da empresa pesquisada.

\section{ELEMENTO DO FRAMEWORK $\quad$ CARACTERISTICAS}

\begin{tabular}{|c|c|}
\hline Definição do Projeto & $\begin{array}{l}\text { O desenvolvimento de produtos e serviços na empresa acontece a } \\
\text { partir do planejamento estratégico de curto prazo, onde há a definição } \\
\text { das premissas estratégicas de acordo com a demanda. As necessidades } \\
\text { do mercado são captadas de acordo com a carteira fixa de clientes e } \\
\text { eventuais encomendas. Estas informações são afuniladas e discutidas } \\
\text { através de setores comercial e desenvolvimento de produtos. Este } \\
\text { último filtra as informações e desenvolve o escopo dos projetos para o } \\
\text { desenvolvimento de produtos, enquanto o comercial é responsável por } \\
\text { definir a viabilidade do desenvolvimento do produto. }\end{array}$ \\
\hline Organização e times de projeto & $\begin{array}{l}\text { O Departamento Comercial recebe a requisição do produto, a qual é } \\
\text { levada à diretoria que avalia a viabilidade do desenvolvimento deste } \\
\text { produto. Quando aprovada a requisição, o projeto é encaminhado ao } \\
\text { setor de Desenvolvimento de Produtos que determina as } \\
\text { especificações e desenho técnico do produto, resultando em um } \\
\text { memorial descritivo, que permite a análise de custos de matéria-prima, } \\
\text { o qual retorna à diretoria para a aprovação da comercialização. }\end{array}$ \\
\hline Gerenciamento e liderança do projeto & $\begin{array}{l}\text { Um grupo composto pelo diretor, líder de fábrica e engenheiro é } \\
\text { responsável pelo gerenciamento e acompanhamento das etapas do } \\
\text { escopo do produto, desde a requisição do cliente até a aprovação para } \\
\text { a comercialização. }\end{array}$ \\
\hline \multirow{3}{*}{$\begin{array}{l}\text { Resolução de problemas, testes e } \\
\text { protótipos }\end{array}$} & $\begin{array}{c}\text { Os protótipos constituem-se no principal meio para validação dos } \\
\text { projetos, modelagem e }\end{array}$ \\
\hline & $\begin{array}{l}\text { Resolução de problemas de projeto e de produção, sendo feitos antes } \\
\text { da finalização do memorial descritivo. Normalmente eles subsidiam } \\
\text { verificações de requisitos. }\end{array}$ \\
\hline & $\begin{array}{l}\text { São realizadas análises técnicas e depois são disponibilizados para a } \\
\text { diretoria. }\end{array}$ \\
\hline Controle e revisão da gerência sênior & $\begin{array}{l}\text { O controle e revisão do processo é controlado pelo setor de qualidade } \\
\text { e PCP, que acompanha os processos de PDP até a entrega do produto. }\end{array}$ \\
\hline $\begin{array}{l}\text { Correções em tempo real e no } \\
\text { decorrer do projeto }\end{array}$ & $\begin{array}{c}\text { O setor de engenharia e qualidade é responsável pelas correções em } \\
\text { tempo real do produto de acordo com as necessidades e viabilidades } \\
\text { decorrentes ao longo da produção. Toda e qualquer alteração é } \\
\text { atualizada no memorial descritivo. }\end{array}$ \\
\hline
\end{tabular}

A análise da empresa permitiu a identificação e sistematização dos setores envolvidos em cada etapa do PDP. As macro-fases do desenvolvimento do produto foram identificadas de acordo com a caracterização de cada uma, já que não existem métodos e técnicas bem definidos na empresa. Similarmente, os documentos gerados variam de acordo com cada projeto, não existindo um formulário a ser preenchido durante as fases, como será sintetizado no Quadro 2. O pré-desenvolvimento do produto é executado pelo núcleo administrativo da empresa, o qual é responsável pela identificação das oportunidades e premissas estratégicas e pelo desdobramento destas estratégias. O setor comercial identifica a necessidade do cliente e 
premissas do mercado, através de pesquisa de mercado e acompanhamento de licitações, gerando relatórios de informações das necessidades atuais do mercado, ou seja, o que está sendo cotado e o que está sendo proposto pelos concorrentes. Estes relatórios são encaminhados à diretoria que faz um estudo da viabilidade e capacidade para a produção do produto de acordo com as ferramentas disponíveis no chão-de-fábrica da empresa, definindo um plano de ação de curto prazo para o desenvolvimento do projeto. O desenvolvimento do produto pode ser dividido em seis fases, sendo que as quatro primeiras fases são de responsabilidade do núcleo operacional, e as outras duas fases, do comercial.

A primeira fase é a concepção de um projeto conceitual, elaborado pelo projetista da fábrica, o qual, de acordo com as necessidades do mercado ou inovação da empresa, elabora o desenho técnico do produto e o memorial, gerando o primeiro memorial técnico do projeto. Com estas informações, a diretoria operacional, o engenheiro e os profissionais da qualidade dão início ao desenvolvimento e testes de protótipos: produzem um protótipo e executam testes físicos no produto para determinação de sua resistência, obtendo o protótipo do produto e um relatório com suas características e resistências. Este protótipo deve ser aprovado pela diretoria e pelo setor da qualidade que fazem uma análise de conformidade comercial para venda, estética, aceitação, preço, conforto e viabilidade de produção, de acordo com o que foi requisitado inicialmente pelo cliente. Se estiver de acordo, o protótipo é aprovado e dado continuidade ao projeto.

A produção é iniciada com o cadastro do produto no ERP da empresa por parte do PCP que libera o produto para comercialização e geração de pedidos pelo setor comercial. O comercial então homologa o produto, definindo uma tabela de preços para a venda do produto desenvolvido, e desenvolve estratégias de vendas e marketing para o seu lançamento, gerando planilhas de metas e controle, além de reuniões para definir estratégias de venda.

O pós-desenvolvimento tem suas ações apoiadas no método de produção puxada da empresa, a qual, por meio dos setores de qualidade e PCP, garante o acompanhamento do produto por meio de relatórios de acompanhamento das vendas, geração de pedidos, emissão de ordem de produção e do faturamento, gerando relatórios de desempenho do produto, de Pedidos e de Ordens de Produção (OPs). As melhorias e atualizações do produto são realizadas com base no acompanhamento das vendas e feedback dos clientes, o que permite a geração de relatórios de mudanças no produto, da performance e da qualidade. 
QUADRO 2 - Elementos do PDP na empresa pesquisada, conforme estrutura de fases.

\begin{tabular}{|c|c|c|c|c|}
\hline $\begin{array}{l}\text { MACRO } \\
\text { FASES }\end{array}$ & FASES & $\begin{array}{c}\text { UNIDADES } \\
\text { ORGANIZACIONAIS }\end{array}$ & $\begin{array}{l}\text { MÉTODOS E } \\
\text { TÉCNICAS }\end{array}$ & $\begin{array}{l}\text { DOCUMENTOS } \\
\text { GERADOS }\end{array}$ \\
\hline \multirow{2}{*}{$\begin{array}{c}\text { Pré- } \\
\text { desenvolvimento }\end{array}$} & $\begin{array}{l}\text { Identificação de } \\
\text { oportunidades e } \\
\text { premissas } \\
\text { estratégicas }\end{array}$ & Setor comercial & $* * *$ & $\begin{array}{l}\text { Relatórios de } \\
\text { Informaçōes de } \\
\text { Mercado }\end{array}$ \\
\hline & $\begin{array}{l}\text { Desdobramento e } \\
\text { execução da } \\
\text { estratégia }\end{array}$ & Diretoria & $* * *$ & $\begin{array}{c}\text { Projetos e Planos } \\
\text { de ação/ Planilhas } \\
\text { de } \\
\text { acompanhamento } \\
\text { e controle }\end{array}$ \\
\hline \multirow{6}{*}{ Desenvolvimento } & Projeto conceitual & Projetista & $* * *$ & $\begin{array}{l}\text { Memorial } \\
\text { téenico }\end{array}$ \\
\hline & $\begin{array}{l}\text { Desenvolvimento } \\
\text { e teste de } \\
\text { protótipos }\end{array}$ & Engenharia/Qualidade/Diretoria & $* * *$ & $\begin{array}{l}\text { Protótipo físico } \\
\text { do produto e } \\
\text { relatório técnico } \\
\text { de resistência. }\end{array}$ \\
\hline & $\begin{array}{l}\text { Aprovação de } \\
\text { produtos }\end{array}$ & Qualidade/Diretoria & $* * *$ & $\begin{array}{l}\text { Protótipo } \\
\text { aprovado }\end{array}$ \\
\hline & $\begin{array}{l}\text { Start-up da } \\
\text { produção }\end{array}$ & PCP & $* * *$ & $\begin{array}{l}\text { Cadastro do } \\
\text { produto }\end{array}$ \\
\hline & $\begin{array}{l}\text { Homologação do } \\
\text { produto }\end{array}$ & Comercial & $* * *$ & Tabela de preços \\
\hline & $\begin{array}{c}\text { Desenvolvimento } \\
\text { das estratégias de } \\
\text { vendas e } \\
\text { marketing }\end{array}$ & Comercial & $* * *$ & $\begin{array}{l}\text { Planilhas de } \\
\text { metas / Planilhas } \\
\text { de controle e } \\
\text { execução } \\
\text { /Reuniāo de } \\
\text { vendas }\end{array}$ \\
\hline \multirow[t]{2}{*}{$\begin{array}{c}\text { Pós- } \\
\text { desenvolvimento }\end{array}$} & $\begin{array}{l}\text { Acompanhamento } \\
\text { do produto }\end{array}$ & Qualidade/PCP & $* * *$ & $\begin{array}{c}\text { Relatório de } \\
\text { desempenho do } \\
\text { produto } \\
\text { /Relatório de } \\
\text { Pedidos } \\
\text { /Relatório de } \\
\text { Ordens de } \\
\text { Produçấo (OP's) }\end{array}$ \\
\hline & $\begin{array}{l}\text { Melhoria e } \\
\text { atualizações }\end{array}$ & Qualidade/PCP & $* * *$ & $\begin{array}{c}\text { Relatório de } \\
\text { mudanças no } \\
\text { produto/ } \\
\text { Relatório da } \\
\text { performance } \\
\text { da qualidade }\end{array}$ \\
\hline
\end{tabular}


A análise da estrutura de fases permite observar que a empresa não possui nenhum método ou técnica sistemática em seu processo de desenvolvimento de produto, já que as estratégias para aquisição de informações limitam-se a um conjunto de atividades coordenadas em cada fase: no pré-desenvolvimento, busca-se as necessidades do cliente e premissas do mercado, através de pesquisa de mercado e acompanhamento de licitações, e é feito um estudo da viabilidade e capacidade para a produção do produto de acordo com as ferramentas da empresa; na fase de desenvolvimento, de acordo com as necessidades do mercado ou inovação da empresa, é feito o desenho e o memorial técnico, produz-se um protótipo e são realizados testes físicos do produto para determinação da sua resistência, em seguida é feita uma análise de conformidade comercial para venda, análise estética, aceitação, preço, conforto e viabilidade de produção, para que seja liberado o produto para comercialização e geração de pedido comercial. Seguese a validação e formatação do preço de venda e lançamento do produto. A fase de pósdesenvolvimento é marcada pela execução de atividades como elaboração de relatórios de acompanhamento das vendas, geração de pedidos, emissão de OPs e faturamento, assim como o acompanhamento das vendas e feedback do cliente.

Quanto à relação de documentos gerados, embora existam produtos em cada uma das fases, o único documento oficial reconhecido por toda a empresa é o memorial técnico, produto da fase do projeto conceitual. A falta de métodos e documentação intermediária tem potencial a gerar problemas de perda de conhecimento ao longo do desenvolvimento do produto, e implica em dificuldade de reaproveitar soluções desenvolvidas no passado que podem resultar em redução do tempo de ciclo de desenvolvimento.

\section{CONCLUSÃO}

A utilização do Framework para o diagnóstico do PDP mostrou-se como uma maneira ágil e eficaz para identificação das principais características, fases e limitações do processo de PDP da empresa. A identificação dos setores envolvidos em cada fase do desenvolvimento do produto, permitiu concluir que a empresa pesquisada, além de não possuir um setor específico para o desenvolvimento de produtos, não tem suas etapas, métodos e técnicas bem definidos, dificultando a gestão de novos projetos e produtos, e, consequentemente, implicando na falta de padronização de documentos gerados em cada uma das fases do PDP. O planejamento estratégico de médio e longo prazo também não é uma prática da empresa, o que implica em falta de organização e desenvolvimento tardio dos produtos, deixando o desenvolvimento dos 
produtos em função do mercado, inviabilizando a criação de produtos de fato inovadores. Diante do cenário econômico atual, as limitações apresentadas pela empresa tornam-na menos competitiva e com baixo poder inovativo, conforme constatado através do seu diagnóstico. Comparando-se com as aplicações anteriores do framework de diagnóstico utilizado, observase que a questão das deficiências em gestão de projetos foram comuns entre os trabalhos de Barbalho e Rozenfeld (2004), Ferreira e Barbalho (2014) e este, mesmo considerando a distância temporal entre os mesmos e o fato de serem aplicados respectivamente a produtos de alta tecnologia, têxteis e mobiliário, o que sugere deficiências sistêmicas em pequenas e médias empresas que desenvolvem produtos, algo a ser estudado com protocolo mais específico no futuro. Outra característica comum foi a dependência com relação à alta gerência, a qual participa de todas as etapas do PDP na empresa e concentra grande espectro de decisões relativas ao processo. Algo a se investigar de maneira mais sistemática no futuro.

Em relação às limitações da pesquisa, pode ser destacada a falta de padronização do processo de desenvolvimento de produto da empresa observada, o que dificultou o detalhamento dos itens apontados no framework. Estas limitações apontam para futuros estudos e possíveis melhorias para o PDP da empresa, para que o setor possa ser mais bem estruturado, com melhores gestões de desenvolvimento de produtos e, consequentemente, melhor capacidade inovativa e competitiva.

\section{REFERÊNCIAS}

BARBALHO, S. C. M.; ROZENFELD, H. Análise do Processo de Desenvolvimento de Produtos de uma Pequena Empresa de Alta Tecnologia. In. Encontro Nacional De Engenharia De Produção, v. 24, 2004.

FERREIRA, R. L.; BARBALHO, S. C. M. . Diagnóstico do PDP de uma empresa têxtil. In: XXXIV Encontro Nacional de Engenharia de Produção, 2014, Curitiga. Anais do XXXIV Encontro Nacional de Engenharia de Produção. Curitiba: Universidade Positivo, 2014. v. Único. p. NA-NA.

MENDES, G.H.S. TOLEDO, J.C. Explorando práticas do desenvolvimento de produtos em pequenas e médias empresas do setor de equipamentos médico-hospitalares. Gest. Prod., São Carlos, v. 19, n. 1, p. 103-117, 2012.

NILVANE BOEHM MANTHEY, N. B.; VERDINELLI, M. A.; ROSSETO, C. R.; CARVALHO, C. E. O impacto da capacidade de inovação no desempenho da inovação de 
produto em PMEs do setor industrial. Revista de Empreendedorismo e Gestão de Pequenas Empresas, v.6, n.2, p. 311-341, Mai/Ago, 2017.

ROZENFELD, H. et al. Gestão de Desenvolvimento de Produtos: Uma Referência Para A Melhoria Do Processo. Sạo Paulo: Saraiva, 2006.

TOLEDO, J. C.; SIMÕES, J. M. S. Gestão do desenvolvimento de produto em empresas de pequeno e médio porte do setor de máquinas e implementos agrícolas do Estado de SP. Gest. Prod., São Carlos, v. 17, n. 2, p. 257-269, 2010

WHEELWRIGHT, S. C.; CLARK, K. B. Revolutionizing product development process: quantum leaps in speed, efficiency, and quality. The Free Press, New York, United States, 1992.

YIN, R. Estudo de caso: planejamento e métodos. Trad. Daniel Grassi. Rev. Cláudio Damacena. 2 ed. Porto Alegre: Bookman, 2001. 